Aslesen, A.R., Nordheim, R., Varegg, B., and Lædre, O. (2018). "IPD in Norway" In: Proc. $26^{\text {th }}$ Annual Conference of the International. Group for Lean Construction (IGLC), González, V.A. (ed.), Chennai, India, pp. 326-336. DOI: doi.org/10.24928/2018/0284.Available at: www.iglc.net.

\title{
IPD IN NORWAY
}

\author{
Andreas R. Aslesen ${ }^{1}$, Runar Nordheim², Bjørn Varegg ${ }^{3}$ and Ola Lædre ${ }^{4}$
}

\begin{abstract}
As projects become more complex and uncertain, the challenge of increasing productivity and improving project outcome becomes greater. Integrated Project Delivery (IPD) seeks to improve project performance through a high level of collaboration between key participants. Although IPD is a well-known delivery model, only a single project has implemented this approach in the Norwegian construction industry: The Tønsberg Project. The purpose of this study is to identify which theoretical IPD elements are used in this project, document experiences from IPD and provide recommendations for the delivery of future IPD projects in Norway.

This article presents research based on a comprehensive literature review and a case study of the first Norwegian IPD project. The case study consists of a document review and 9 semi-structured interviews with key informants.

The experiences established through this research indicate that a higher level of collaboration facilitates innovative design and effective execution. The interviewees consider IPD to have potential to improve the performance of future projects but describe change in culture to be crucial for project success.

This study presents challenges and benefits experienced in The Tønsberg Project. It provides practitioners with a framework of theoretical IPD elements and first-hand experiences with how these elements can affect project performance.
\end{abstract}

\section{KEYWORDS}

Integrated Project Delivery (IPD), collaboration, trust, case study, recommendations.

\section{INTRODUCTION}

Studies show various problems, such as adversarial relationships, low productivity rates and frequent failure to meet the owner's expectations in the AEC industry(Mitropoulos \& Tatum 2000; Thomsen, et al. 2009). A report developed by the Norwegian Ministry of Local Government and Modernization states that the productivity rates in the Norwegian construction industry have declined from the mid-90s (KMD 2012). As projects become

\footnotetext{
M.Sc. student, Department of Civil and Environmental Engineering, Norwegian University of Science and Technology (NTNU), Høgskoleringen 7A, 7491 Trondheim

M.Sc. student, Department of Civil and Environmental Engineering, NTNU

M.Sc. Lead Contract and Procurement, Vestfold Hospital Trust

Associate professor, dr.ing, Department of Civil and Environmental Engineering, NTNU
} 
more complex and uncertain, the challenge of improving the project delivery and optimizing project outcomes becomes greater.

Traditional delivery approaches can often be characterized by fragmented teams, disputes within the project organization and problems related to the interface between design and construction. The parties tend to work in isolated siloes focusing on their own interests (Mei, et al. 2013; Thomsen, et al. 2009). Consequently, the project parties have a low degree of common understanding and a high degree of individual interests in the project, which often results in inefficient project delivery.

There is limited documentation related to IPD in the Norwegian construction industry. By collecting data from Norway's first IPD project, named The Tønsberg Project, this research seeks to fill this gap of knowledge. Consequently, the purpose of this study is to identify which of the theoretical IPD elements that are being used and present the experienced effects and challenges related to the individual elements. Based on these experiences, this article provides a framework with respect to which of the theoretical IPD elements future projects should implement.

The Tønsberg Project is an on-going pilot IPD project in the Norwegian construction industry. A limitation of this study is that the results presented in this article are based solely on this individual project.

\section{METHOD}

This study is based on a qualitative research method, with multiple sources of data. The theoretical IPD elements were identified in a literature study, based on the five steps presented by Blumberg, et al. (2014). The search was carried out using internationally acknowledged databases. A systematic search strategy, where key words such as "Integrated Project Delivery", "Relational Contract", "Culture", "Target Value Design" and "Lean" in combination and with various search functions, provided a wide range of relevant literature.

The research presented in this article is established through a comprehensive singlecase study. The Tønsberg Project was selected as case seeing that it is the first IPD project in Norway. Yin (2009) describes single-case studies to be rational if they represent "revelatory" cases, where the situation has not been accessible to social science. Because it provides the first experiences with IPD in the Norwegian construction industry, a single-case study is considered to be expedient. The project is a complex building project within the Norwegian health care sector, consisting of a $31,000 \mathrm{~m}^{2}$ somatic building and a 12,000 $\mathrm{m}^{2}$ psychiatry building, with an estimated cost of approx. 370 million USD and is set to be completed in 2021.The Lead Contract and Procurement manager in The Tønsberg Project is co-author of this article, which provides a unique insight into the project's delivery.

The case study started with a review of the project's IPD agreement, a pre-project report and powerpoint-series previously used by the project participants. This was done in order to get an initial overview of the project. Then 9 semi-structured in-depth interviews with representatives from all major project participants. More specifically, 4 interviewees represented the client, 2 represented the main contractor, 2 represented the design team 
and 1 represented a key sub-contractor. They were selected since they oversee overall project delivery and day-to-day operations.

The research's validity is considered satisfactory as the findings is based on multiple sources of information, such as literature, documents and interviews. The research's reliability is assumed to be reduced as a consequence of the face that The Tønsberg Project is considered prestigious for the participants. However, interviewing representatives from all major participants, having informants confirming the transcripted interviews and involving the Lead Contract and Procurement manager is believed to increase the reliability.

\section{THEORETICAL FRAMEWORK}

IPD is a delivery model that accommodates the construction industry's need for more efficient collaboration between project participants. Therefore, the delivery model has similarities to other models based on relational contracts, such as project partnering and project alliancing (Lahdenperä 2012). These delivery models seek to solve some of the problems related to traditional delivery models. Matthews and Howell(2005)present four major problems with traditional and transactional contractual approaches (Table 1):

Table 1: Problems related to traditional delivery approaches (Based on Matthews and Howell (2005))

\begin{tabular}{|c|c|c|}
\hline Problem & Underlying cause & Results \\
\hline $\begin{array}{l}\text { Good ideas are } \\
\text { held back }\end{array}$ & $\begin{array}{l}\text { Lack of commitment from trade } \\
\text { contractors based on competition. Ideas } \\
\text { are held back in the design to keep a } \\
\text { competitive advantage }\end{array}$ & $\begin{array}{c}\text { Inefficient design, changes, } \\
\text { low degree of innovation }\end{array}$ \\
\hline $\begin{array}{l}\text { Contracting limits } \\
\text { cooperation and } \\
\text { innovation }\end{array}$ & $\begin{array}{c}\text { Subcontractors contracts state what each } \\
\text { individual trade are responsible to } \\
\text { provide }\end{array}$ & $\begin{array}{c}\text { Subcontractors struggle to } \\
\text { collaborate, low degree of } \\
\text { innovation and common } \\
\text { understanding }\end{array}$ \\
\hline $\begin{array}{l}\text { Inability to } \\
\text { coordinate }\end{array}$ & $\begin{array}{l}\text { No formal effort to link the planning } \\
\text { systems of the various subcontractors }\end{array}$ & $\begin{array}{l}\text { Inefficient project delivery, } \\
\text { potential disputes }\end{array}$ \\
\hline $\begin{array}{l}\text { Pressure for local } \\
\text { optimization }\end{array}$ & $\begin{array}{l}\text { Participants wish to sustain their } \\
\text { individual interest }\end{array}$ & $\begin{array}{l}\text { Individual parties interest } \\
\text { being prioritized over the } \\
\text { project interests }\end{array}$ \\
\hline
\end{tabular}

Collaborative delivery models seek to solve these problems by aligning project objectives with the interests of key participants and implementing Lean expediently (Matthews \& Howell 2005).

Asmar, et al. (2013) compares the performance of 12 IPD projects with 23 projects delivered with more traditional approaches. Their comprehensive study provides statistical data showing significant superior performance related to quality, communication, change performance, schedule, and environmental sustainability, with no significant cost premium. Their study was generally based on complex building projects, 
where approximately $50 \%$ of the projects were health care facilities. Furthermore, Cheng (2016) provided research showing examples of projects achieving success with IPD regardless of project type, scope, location or previous experiences with IPD. Her report of ten successful projects in the US and Canada using an integrated form of agreement illustrates how projects using IPD and Lean are more likely to meet owner's goals and achieve success within costs and schedule.

Thomsen, et al. (2009) defines three basic domains that all project delivery systems operate within: "commercial terms", the project's "operating system" and "project organization". Contractual IPD elements, such as early involvement of key participants, mutual benefit and reward and liability waivers, provide "commercial terms" that align the project participants' interests with the project objectives. This facilitates collaboration and a much higher level of common understanding between the "major players" of the project (Thomsen, et al. 2009).IPD project's "operating system" seeks to increase efficiency by implementing integrated technology, information systems, and often Lean construction processes and tools, based on collaborative delivery (Thomsen, et al. 2009). Cheng (2016) illustrates the importance of a collaborative "project organization" and describes it as being "fostered" by IPD contracts and Lean processes and tools. This leads to an integrated project delivery where the contract and culture provides the framework for collaboration, while processes and technological tools facilitate a more efficient project delivery.

Table 2 illustrates theoretical IPD elements divided into the overall categories of Contract, Technology and Processes and Culture. The categories are based on earlier work, presented by Lee, et al.(2014)and respectively are similar to "commercial terms", “operating system” and "project organization" presented by Thomsen, et al. (2009).

Table 2: Theoretical IPD elements (Adapted from Lee et al. 2014)

\begin{tabular}{|c|c|c|c|c|c|}
\hline IPD elements & $\begin{array}{l}\text { (AIA } \\
\text { 2007) }\end{array}$ & $\begin{array}{c}\text { (NASFA, } \\
\text { et al. } \\
2010)\end{array}$ & $\begin{array}{c}\text { (Ghassemi } \\
\text { \& Becerik- } \\
\text { Gerber } \\
\text { 2011) }\end{array}$ & $\begin{array}{l}\text { (Lee, et } \\
\text { al. 2014) }\end{array}$ & $\begin{array}{c}\text { (Pishdad- } \\
\text { Bozorgi \& } \\
\text { Beliveau } \\
\text { 2016) }\end{array}$ \\
\hline \multicolumn{6}{|l|}{ Contract } \\
\hline Multiparty Contract & & $\mathrm{X}$ & $\mathrm{X}$ & $X$ & $X$ \\
\hline Shared Risk and Reward & $\mathrm{X}$ & $X$ & $X$ & $X$ & $X$ \\
\hline $\begin{array}{c}\text { Early Involvement of Key } \\
\text { Participants }\end{array}$ & $\mathrm{X}$ & $\mathrm{X}$ & $X$ & $X$ & $X$ \\
\hline Intensified Planning & $\mathrm{X}$ & $X$ & & & $\mathrm{X}$ \\
\hline $\begin{array}{c}\text { Collaborative Decision } \\
\text { Making }\end{array}$ & $\mathrm{X}$ & $\mathrm{X}$ & $\mathrm{X}$ & $X$ & $X$ \\
\hline Collaborative Goal Definition & $\mathrm{X}$ & $X$ & $\mathrm{X}$ & & $X$ \\
\hline Liability Waivers & & $\mathrm{X}$ & $\mathrm{X}$ & $X$ & $X$ \\
\hline Financial Transparency & & & & $X$ & $X$ \\
\hline
\end{tabular}




\begin{tabular}{ccccc}
$\begin{array}{c}\text { Technology and Processes } \\
\text { Lean }\end{array}$ & & & \\
BIM & & $\mathrm{X}$ & $\mathrm{X}$ \\
Integrated Information & $\mathrm{X}$ & & $\mathrm{X}$ & $\mathrm{X}$ \\
Culture & & & & \\
Mutual Respect and Trust & $\mathrm{X}$ & $\mathrm{X}$ & $\mathrm{X}$ & $\mathrm{X}$ \\
Willingness to Collaborate & & & $\mathrm{X}$ & \\
Open Communication & $\mathrm{X}$ & $\mathrm{X}$ & $\mathrm{X}$ & $\mathrm{X}$ \\
Co-location & & & & $\mathrm{X}$ \\
\hline
\end{tabular}

The references presented in Table 2 are considered credible and are frequently cited in relevant literature. By examining the table, it is clear that the focus on cultural elements in literature has increased over recent years. The cultural aspects of IPD have become more relevant in literature, as the industry gains more experiences with the delivery model. This illustrates the importance of a collaborative culture in IPD projects.

\section{FINDINGS AND DISCUSSION}

The Tønsberg Project has embraced the IPD methodology and to a certain extent implemented all the theoretical IPD-elements presented in the theoretical framework. The collected data indicates an efficient project delivery system, where most of the desired effects of IPD are achieved. The project has nevertheless experienced some challenges, and the findings indicate that it is possible to learn from the project's experiences to deliver future IPD projects more efficiently.

\section{EXPERIENCES AND RECOMMENDATIONS RELATED TO THE CONTRACT}

As the first IPD project in Norway, the project owner had to examine the procurement process. The lack of experience in the Norwegian industry could potentially lead to scepticism and an unsatisfactory response from the industry. The project owner used a strategy where the procurement of key participants was based on traditional Norwegian contract regulations and supplemented with a letter of intent. This stated that the parties agreed to collaboratively develop a multiparty contract, customized for the Norwegian construction industry. The IPD-agreement was developed and signed during the feasibility study. All traditional contract regulations were terminated and replaced with IPD-regulations in the new contract. In the development of the agreement, the legal team based their work on the American multiparty-agreement: The Integrated Form of Agreement (IFOA). The interviewees describe that the IPD agreement has worked efficiently and, although it is recommended to make small changes, it would be expedient to use this agreement in future IPD projects in Norway. The changes mentioned by interviewees are related to Norwegian zing the contract to a larger degree than in The Tønsberg Project and customizing the contract to project specific circumstances.

The key project participants have shared risk and reward, where the designers, contractor, and three technical subcontractors out their profit at risk. If the project's actual cost becomes greater than the target cost at completion, the participants' profit is reduced 
by the corresponding amount. Should, on the other hand, the actual cost become lower than target cost, the profit will increase with $50 \%$ of the savings. The owner will in this case receive the remaining $50 \%$.It is considered important to involve key subcontractors so that a considerable part of the project cost is included in the shared compensation structure. Another benefit of including both the contractor and the technical subcontractors in the shared risk/reward-pool is that they provide relevant competence, and therefore contribute to effective structural and technical solutions. The shared risk and reward in The Tønsberg Project is considered as an important economic incentive to collaborate and has aligned the participants' interests.

There has been early involvement of key participants in The Tønsberg Project, where designers, contractor, and three technical subcontractors were involved in the early stages of the feasibility study. This has been an important factor to minimize the project's costs of change orders. A collaborative project delivery has facilitated effective solutions that are best for the project, based on a high degree of common understanding while there are still substantial opportunities for influence, which makes it likely to assume that the cost of changes has reduced drastically compared to traditional delivery approaches(Figure 1). Despite the contractor being involved early, key personnel with hands-on experiences in production were working on other projects and did not participate before the production phase. It is likely to assume that potential for positive effects is greater if the project could exploit the competence of this personnel. Future IPD contracts should therefore specify that key personnel from contractors should be involved in design.
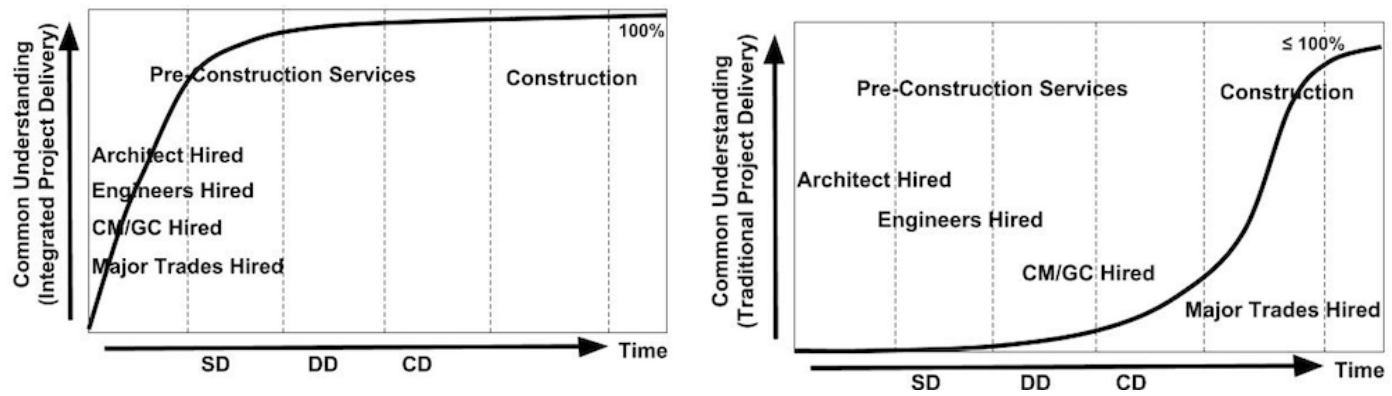

Figure 1: Degree of Common Understanding (Adapted from Lichtig (2008))

The Tønsberg Project did not achieve the desired amount of intensified planning. In the closing stages of the feasibility study, the estimated cost became approximately $20 \%$ above the investment budget. This led to some challenging processes, which resulted in less time and resources for planning the project than originally planned. To avoid this in future IPD projects, it is recommended to set sufficient time for intensified planning. It is also important not get too caught up in the project's concept during the feasibility study, but rather to seek to reduce cost drivers early.

Collaborative decision-making processes have been causing some of the greatest challenges in the project. The project organization has experienced inefficient decisionmaking processes because of the collaborative "leadership by all" approach, where all the parties must agree upon a decision. As a result of the passive decision-making culture, 
these processes have become far more time-consuming than with traditional delivery. Future projects need to solve these issues in order to achieve a reasonable decisionmaking culture. They can benefit by establishing a clear organizational hierarchy, specifying roles and expectations in the IPD agreement or implementing decision-making procedures. Another alternative is to hire external consultants to facilitate the decisionmaking processes. By combining either of these alternatives with a clear decision-making plan, future projects can facilitate more efficient decision-making.

There has not been a fully collaborative goal definition in The Tønsberg project. The project's target cost and main schedule are project goals that have been developed collaboratively. However, the general project goals were developed by the project owner during the feasibility study. Some of the project participants considered the goals to be somewhat unrealistic and expressed that fully collaborative goal definitions could make project participants feel a greater sense of ownership with respect to the project. It is considered beneficial for future IPD projects to collaboratively develop realistic goals.

Liability waivers have become crucial for participants to alter their traditional approach to deviations. The focus, that is traditionally on who is to blame for deviations, is now on finding solutions that are best for the project. This results in fewer conflicts and facilitates efficient processes to solve deviations.

Financial transparency is described by the interviewees as critical for collaboration, especially considering necessary trust related to compensation structures. Some project participants are competitors and will compete for future projects, which has made it challenging and restrained opportunities for full financial transparency. However, the desired degree of financial transparency has been achieved.

\section{EXPERIENCES AND RECOMMENDATIONS RELATED TO TECHNOLOGY AND PROCESSES}

The project can be considered as one of the leading projects in the Norwegian industry using Lean design and construction. It has implemented Last Planner, Target Value Design, ICE-meetings, A3-reports, Reliable Promising, and Continuous Improvement. Experiences indicate that Lean design and construction has increased efficiency and reduced waste significantly in The Tønsberg Project.

The Tønsberg project has experienced success using BIM. The project implemented virtual design and construction, and won the prize for "Design using open technology" at the building SMART International Awards 2017. An interviewee reflected how the selection of technological tools and processes should be based on desired effects, not previous experiences and preferences. Future projects should share BIM models, evaluate desired effects, and consider implementing innovative technology and processes.

Integrated information systems have been implemented in project delivery. This has organized the information and made it more available, while providing all the participants with an accurate representation of the project. The data shows various opinions related to these systems. Some are embracing them, while others find it hard to adapt to new ways of processing information. Future projects could benefit from having someone responsible for sorting the information and making a clear and transparent information 
structure. E-learning courses, where personnel can learn about the information system, could also help workers find and handle relevant information.

\section{EXPERIENCES AND RECOMMENDATIONS RELATED TO CULTURE}

The data collected, indicates that the project has implemented all the theoretical IPD elements related to culture. To achieve the desired effects of IPD, it is described by interviewees as crucial for project organization to base delivery on a collaborative culture. This is the foundation of the delivery, and it is important for all major participants to alter their traditional mind-sets and behaviour to a collaborative approach. Interviewees consider the project's contractual framework and co-location (3-4 days a week) as important IPD elements to facilitate the collaborative culture. The project organization has, in addition to the mentioned IPD elements, made some specific efforts to facilitate the achievement of cultural IPD elements. These additional efforts are presented in table 3.

Table 3: Efforts made in The Tønsberg Project to facilitate a collaborative project culture

\begin{tabular}{|c|c|c|}
\hline Additional efforts & Description & $\begin{array}{l}\text { Desired cultural } \\
\text { IPD element }\end{array}$ \\
\hline $\begin{array}{l}\text { More selection criteria } \\
\text { than price in the } \\
\text { procurement process }\end{array}$ & $\begin{array}{c}40 \% \text { project crew, } 40 \% \text { delivery and } \\
20 \% \text { price }\end{array}$ & $\begin{array}{l}\text { Willingness to } \\
\text { collaborate }\end{array}$ \\
\hline Initial presentations & $\begin{array}{c}\text { Presentations by potential participants in } \\
\text { the procurement process }\end{array}$ & $\begin{array}{l}\text { Willingness to } \\
\text { collaborate }\end{array}$ \\
\hline $\begin{array}{l}\text { Focus on social relations } \\
\text { across organizational } \\
\text { boundaries }\end{array}$ & $\begin{array}{l}\text { Create relations trough social events, } \\
\text { shared lunch room, Big Room meetings }\end{array}$ & $\begin{array}{l}\text { Mutual respect and } \\
\text { trust }\end{array}$ \\
\hline "House rules" & Guidelines for behaviour on co-location & Open communication \\
\hline Big Room & $\begin{array}{l}\text { Meetings to keep the entire project } \\
\text { organization keep updatedPresentations } \\
\text { for education and training }\end{array}$ & Open communication \\
\hline $\begin{array}{l}\text { Prepared to replace } \\
\text { "rotten apples" }\end{array}$ & $\begin{array}{c}\text { Change personnel or project participants } \\
\text { that does not adapt to the collaborative } \\
\text { project culture }\end{array}$ & $\begin{array}{l}\text { Willingness to } \\
\text { collaborate }\end{array}$ \\
\hline Leadership support & $\begin{array}{c}\text { Leaders signalizing expectations and } \\
\text { attitudes }\end{array}$ & $\begin{array}{l}\text { Willingness to } \\
\text { collaborate }\end{array}$ \\
\hline
\end{tabular}

The research carried out indicates that the project could benefit from focusing even more on building relationships in order to create a collaborative project culture. In the procurement process of The Tønsberg Project, the project owner focused on experiences with collaborative methods, and potential participants held presentations. To identify participants that are willing to collaborate to an even higher degree, interviews with potential participants in the project procurement are considered expedient.

Training and education are described by interviewees as important and they consider E-learning courses as beneficial for future projects. These courses can provide individual learning and can reduce waste by avoiding excessive educational presentations. E- 
learning courses can provide informative introductions to the project and teach important IPD methodology focusing on the transition from traditional delivery approaches to IPD.

Another element that can facilitate a collaborative project culture within the project organization is shared values. This is a cultural element that can affect the project positively by aligning participant attitudes and expectations with project objectives.

\section{CONCLUSION}

The Tønsberg Project has experienced positive effects using IPD, and the interviewees generally apprised the implementation. The research set out to identify which theoretical IPD elements are being used in the first Norwegian IPD project, to document experiences from the use of IPD, and to provide recommendations for future IPD projects.

The Tønsberg Project has implemented all the theoretical IPD elements presented in this paper. However, the desired degree of intensified planning was not achieved, the general performance goals were not defined collaboratively, and participants are not colocated "full-time" but rather 3-4 days a week.

Experiences from the project, which show various effects with individual elements, reflect how IPD facilitates collaboration and a higher level of common understanding between the key project participants. Several interviewees describe a culture where decisions are being made based on what is considered best for the project, which results in optimal solutions based on a high degree of common understanding and communication between the project participants. Although the research does not provide quantifiable metrics to support these statements, the interviewees described this as aspects that will lead to a drastic reduction in the cost of changes, compared to traditional projects.

All the theoretical IPD elements are recommended in future IPD projects. Table 4 presents specific recommendations related to the project delivery of future IPD projects. In addition to these recommendations, interviewees find shared values for the project organization as a potential cultural element that could benefit future IPD projects.

Table 4: What future IPD projects in Norwayshould pursuefrom The Tønsberg Project

\begin{tabular}{cc}
\hline IPD element & Recommendations for future IPD projects in Norway \\
\hline Contract & Customize to the Norwegian industry, include key \\
subcontractors
\end{tabular}




\begin{tabular}{|c|c|}
\hline Collaborative Goal Definition & $\begin{array}{c}\text { Define all goals } \\
\text { (Including general performance goals) }\end{array}$ \\
\hline Liability Waivers & For the risk-pool parties \\
\hline Financial Transparency & For the risk-pool parties \\
\hline \multicolumn{2}{|l|}{ Technology and Processes } \\
\hline Lean & Use to reduce waste \\
\hline BIM & Shared model for project participant \\
\hline Integrated Information & Transparent information structure, E-learning courses \\
\hline \multicolumn{2}{|l|}{ Culture } \\
\hline Mutual Respect and Trust & Build social relations \\
\hline Willingness to Collaborate & $\begin{array}{c}\text { More selection criteria than price, presentations (and } \\
\text { interviews), replace "rotten apples", leadership support, E- } \\
\text { learning courses }\end{array}$ \\
\hline Open Communication & House rules, Big Room \\
\hline Co-location & Full-time co-location (More than 3 days per week) \\
\hline
\end{tabular}

The result of this study is based on a single-case study. In order to provide more representative results, future research should collect data from a wider range of IPD projects in Norway. It is also considered expedient to prioritize the importance of each individual IPD element based on its cost/benefit.

The recommendations presented is this article focus on the owners' perspective. This offers a comprehensive overview asthe project owner is the party responsible for founding the project and choosing a strategy for the projects delivery.

\section{REFERENCES}

AIA (2007). "Integrated Project Delivery: A Guide." The American Institute of Architects.

Asmar, M. E., Hanna, A. S \&Loh, W.-Y. (2013). "Quantifying Performance for the Integrated Project Delivery System as Compared to Established Delivery Systems" Journal of Construction Engineering and Management,139(11).

Blumberg, B.F., Cooper, D. R. \& Schinder, P. S. (2014). Business Research Methods, McGraw Hill, London.

Cheng, R. (2016). "Motivation and Means: How and Why IPD and Lean Lead to Success.'Univericy of Minnesota.

Ghassemi, R. \&Becerik-Gerber, B. (2011). "Transitioning to Integrated Project Delivery: Potential Barriers and Lessons Learned."Lean Construction Journal, 2011, 32-52.

KMD (2012).“Meld. St. 28 (2011-2012) - Gode bygg for eit betre samfunn.” Kommunalog moderniseringsdepartementet.

Lahdenperä, P. (2012). "Making sense of the multi-party contractual arrangements of project partnering, project alliancing and integrated project delivery. "Construction Management and Economics, 30(1), 57-79. 
Lee, H., Anderson, S. M., Kim, Y. \& Ballard, G. (2014). "Advancing Impact of Education, Training, and Professional Experience on Integrated Project Delivery." Practice Periodical on Structural Design and Construction, 19(1), 8-14.

Lichtig, W. (2008). "Intro to Lean Design Seattle 2008."McDonough Holland \& Allan Attorneys at Law, Powerpoint presentation sides. <https://www.leanconstruction.org/media/docs/wpapers/intro200809/Relational $\% 20$ Contracting\%20-\%20Will\%20Lichtig/Relational\%20Contracting\%20$\% 20$ Will\%20Lichtig.pdf> (24Apr18)

Matthews, O. \& Howell, G. A. (2005). "Integrated Project Delivery an Example of Relational Contracting."Lean Construction Journal. 2(1), 46-61.

Mei, L., Griffis, F. H. \& Bates, A. J. (2013). "Compensation Structure and Contingency Allocation in Integrated Project Delivery."Proc., 120 th ASEE Annual Conference and Exposition, American Society for Engineering Education, Atalanta.

Mitropoulos, P. \& Tatum, C. B. (2000). "Forces Driving Adoption of New Information Technologies."Journal of Construction Engineering and Management, 126(5), 340348.

NASFA; COAA; APPA; AGC \& AIA (2010). "Integrated Project Delivery for Public and Private Owners."National Association of State Facilities Administration.

Pishdad-Bozorgi, P. \& Beliveau, Y. J. (2016). "Symbiotic Relationships between Integrated Project Delivery (IPD) and Trust."International Journal of Construction Education and Research, 12(3), 179-192.

Thomsen, C., Darriongton, J., Dunne, D. \&Lichtig, W. (2009).“Managing Integrated Project Delivery." CMAA.

Yin, R. K. (2009). Case Study Research: Design and Methods, SAGE,Pennsylvania 